\title{
Difusão de tecnologia e sexismo nas Ciências Agrárias
}

\author{
Diffusion of technology and sexism in the agricultural sciences
}

\author{
Ana Louise de Carvalho Fiúza ${ }^{\mathrm{I}}$ Neide Maria de Almeida Pinto ${ }^{\mathrm{II}}$ Tiago Nogueira Galinari ${ }^{\mathrm{II}}$ \\ Vanessa Aparecida Moreira de Barros ${ }^{\mathrm{IV}}$
}

\section{RESUMO}

Este trabalho analisa a percepção predominante, no meio rural, de que a tecnologia é um produto relacionado ao universo masculino. Nesta pesquisa, são trazidos dados que evidenciam o grande distanciamento das mulheres rurais do acesso ao conhecimento tecnológico, produzido e difundido dentro da universidade, que está direcionado para a melhora da qualidade de vida e para as possibilidades de aumento na geração de renda no meio rural, mas ao qual elas ainda têm acesso insignificante. Trabalhou-se, nesta pesquisa, com a coleta de dados obtidos nos cursos oferecidos durante a Semana do Fazendeiro, ao longo de quatro anos, de 2004 a 2007, correlacionando a cada um dos cursos oferecidos a frequência de homens e mulheres nestes. Concluímos que o sexismo tecnológico se perpetua nos modelos de gestão das unidades produtivas no meio rural, que consideram a mulher em uma condição hierárquica de complementaridade e não como cogestora da unidade produtiva familiar, condição que lhe restringe o acesso a informações e conhecimentos técnicos, gerenciais, ambientais e de organização de grupos.

Palavras-chave: tecnologia para o meio rural, trabalho feminino, trabalho produtivo e reprodutivo.

\section{ABSTRACT}

This study examines the perception prevalent in rural areas of technology as a product related to the male universe. Bring this research data that show the great distance of rural women's access to technological knowledge, produced and distributed within the university, which is directed to the improvement of quality of life and possibilities to increase the generation of income in rural areas, but the which they still have access insignificant. Worked on this research with the collection of data obtained in courses offered during the Week of the Farmer, over four years, from 2004 to 2007, correlating to each of the frequency of courses offered to men and women to them. We conclude that it perpetuates sexism technological models in the management of production units in rural areas as the woman in a hierarchical condition of complementarity and not as co-manager of the plant family, a condition which restricts access to information and expertise, management, and organization of environmental groups.

Key words: technology for rural areas, women, reproductive and productive work.

\section{INTRODUÇÃO}

Apesquisa "Geração/Difusão de Tecnologia e Sexismo nas Ciências Agrárias”, que ora apresentamos os resultados, teve como motivação para a sua realização a problematização do sexismo no campo da produção e na difusão de tecnologias voltadas para o meio rural. Por meio desta pesquisa, procurou-se apresentar evidências relativas à assimetria posicional a que a mulher está submetida no meio rural, com as implicações daí advindas para o campo de possibilidades de desenvolvimento de suas capacidades. Tivemos como objetivo, neste trabalho, mostrar que essa subalternidade posicional da "mulher rural" tem se mantido dentro de um círculo vicioso, cultural-institucional, que pode ser evidenciado na manutenção das desigualdades de acesso da mulher aos conhecimentos científico-tecnológicos voltados

\footnotetext{
IDepartamento de Economia Rural, Universidade Federal de Viçosa (UFV), Viçosa, MG, Brasil.

${ }^{\mathrm{II} D e p a r t a m e n t o ~ d e ~ E c o n o m i a ~ D o m e ́ s t i c a, ~ U F V, ~ V i c ̧ o s a, ~ M G, ~ B r a s i l . ~}$

IIIDepartamento de Economia Rural, UFV. Rua Virgílio Val, nº 08, ap. 204, Centro, 36570-000, Viçosa, MG, Brasil. E-mail: tiago.galinari@ufv.br. Autor para correspondência.

${ }^{\text {IV}}$ Departamento de Economia Doméstica, UFV, Viçosa, MG, Brasil.
} 
para o meio rural em eventos supostamente abertos a qualquer pessoa disposta a frequentá-lo, seja homem ou mulher. É problematizada, neste artigo, a seguinte questão: embora exista essa possibilidade de acesso ao conhecimento científico-tecnológico em eventos abertos ao público em geral, essa possibilidade não está, de fato, construída culturalmente. Por exemplo, quando percebe-se que, no Brasil, os homens praticam futebol em número muito mais significativo que as mulheres, não se está querendo dizer que haja uma proibição às mulheres de jogarem futebol, mas, sim, afirmar que existe uma construção cultural que incentiva o homem a jogar futebol e praticar esportes, enquanto tal prática esportiva não é legitimada da mesma forma para a mulher, embora tal prática não lhe seja proibida. Ou seja, a cultura se coloca como uma demarcadora de condutas. Quando são observados os dados relativos à frequência de homens e mulheres aos cursos oferecidos na Semana do Fazendeiro, fica evidenciada uma clara divisão sexual: aqueles cursos referentes às atividades voltadas para o mercado de produtos de renda "miúda" ou de segunda grandeza, como artesanato, biscoitos, pães, queijos, doces, geleias, etc., são frequentados, predominantemente, por mulheres, já aqueles relativos a atividades voltadas para o mercado de produtos de renda "graúda”, como criação animal e produção vegetal, são predominantemente frequentados por homens. Desse modo, entendendo o conceito de sexismo como a perpetuação de hierarquias de gênero em determinadas esferas da sociedade (HARAWAY, 2000; SHIENBINGER, 2001), fica perceptível que esse fenômeno tem, claramente, um caráter sexista. Isso porque, mesmo não existindo um impedimento formal de participação das mulheres nesses cursos, a restrição cultural existe e precisa ser percebida pelas instituições que promovem tais eventos e, principalmente, pelas instituições de assistência técnica e extensão rural, a fim de que essas oportunidades de acesso ao conhecimento científicotecnológico possam ser estendidas, de fato, a uma gama maior de pessoas que vivem e trabalham no meio rural. Se a porcentagem de mulheres que têm acesso ao conhecimento científico-tecnológico aumenta, estará aumentando, também, a porcentagem da população que pode alterar os indicadores de desenvolvimento socioeconômico de uma região.

Um primeiro ponto a ser destacado no que se refere à questão da desigualdade das mulheres rurais referente à possibilidade de acesso a conhecimentos tecnológicos está relacionado ao fato de seu trabalho ser concebido como estando ligado à esfera reprodutiva, de cuidado da casa e da família. Segundo FRASER (1987) e BENERIA (2006), a designação esfera produtiva e reprodutiva pode ser dada a partir da ascensão do capitalismo burguês, no século XIX, quando ocorre uma evasão das atividades realizadas em âmbito doméstico para a esfera pública, entendida como aquela relativa à esfera da economia e do Estado.

A concepção da sociedade dividida em uma “esfera pública”, onde se desenrolam os assuntos relativos à vida econômica e política, próprios ao homem, e outra "privada”, voltada para as questões domésticas, religiosas e do âmbito da subjetividade, percebidas socialmente como próprias da mulher, passa, desde o século. XIX, com a ascensão da burguesia, a ser legitimada como naturalmente dada e não como historicamente construída, até mesmo por autores críticos da sociedade capitalista, como Marx e Habermas. Dentro desse processo de naturalização da esfera pública como masculina e da privada como feminina, FRASER (1987) e NICHOLSON (2000) chamam a atenção para o fato de que assume-se de forma natural a dissociação entre as esferas ditas produtivas e reprodutivas, desconsiderando-se, em primeiro lugar, o imbricamento entre elas e, em segundo lugar, o fato de que a mulher está presente em ambas as esferas, só que de forma subjugada. Segundo NICHOLSON (2000), as tarefas realizadas pelas mulheres, de cuidado com os filhos, futuros trabalhadores, de limpeza da casa, das roupas, de preparação dos alimentos, dentre outras tarefas, são fundamentais para a reprodução do capital, visto que são realizadas gratuitamente pela "esposa”, mãe de família. Caso essas atividades tivessem que ser pagas, os salários pagos aos trabalhadores teriam que ser muito mais altos para que eles conseguissem se manter sadios e produtivos, e as crianças limpas, alimentadas, tratadas e educadas.

Já FRASER (1987) estabelece as suas críticas à teoria crítica de Habermas começando por mostrar que a dicotomia por ele criada entre “reprodução material” e "reprodução simbólica”, referindo-se, respectivamente, a alimentos e bens produzidos na esfera da economia de mercado e à socialização das crianças na esfera privada, está equivocada. A autora esclarece que tal separação está enviesada, visto que o cuidado das crianças não se resume aos aspectos relativos à sua socialização, como o aprendizado da língua e das normas de comportamento e de convivência, mas, inclui, também, cuidados físicos, que poderiam claramente se encaixar como fazendo parte da esfera da "reprodução material", tais como: cuidados com as doenças infantis, vigilância face aos riscos de lesões e ferimentos nas brincadeiras. Enfim, o cuidado das crianças envolve tanto aspectos relativos à "reprodução simbólica" como da 
“reprodução material”. Por outro lado, os alimentos e bens produzidos na esfera da "reprodução material" não estão isentos de aspectos simbólicos, envolvendo a valorização dos alimentos. Essa divisão entre esfera pública e privada que torna invisível, tanto o trabalho que a mulher desenvolve na dita esfera produtiva, como também a forma como o trabalho na esfera reprodutiva é fundamental para a realização do trabalho na esfera produtiva, tem uma base cultural, variando de sociedade para sociedade e de contexto para contexto o seu grau de acesso aos conhecimentos tecnológicos. Ou seja, não seria a técnica em si que conteria uma restrição à mulher, mas, antes, os preceitos culturais que trariam essas restrições. HABERMAS (2001) apoia essa afirmação por considerar que a técnica em si não conteria já em sua imanência uma racionalidade do dispor, uma racionalidade da dominação, no caso, a masculina. Pelo contrário, a técnica teria uma racionalidade própria. Assim, uma tecnologia não seria, a princípio, em si mesma, sexista, ou seja, restrita, destinada ou apropriada para um ou outro sexo. Seria dentro de sua institucionalização na sociedade e no próprio campo científico que esse sexismo da ciência se configuraria.

Uma das vias para a instauração da discriminação sexista no acesso ao conhecimento teria se dado, segundo SCHIENBINGER (2001), por meio da própria ciência. Grandes pensadores e filósofos afirmaram, desde a Grécia Antiga até os dias hoje, a incapacidade da mulher para o pensar abstratamente, para fazer generalizações e realizar cálculos objetivos. Essa concepção socialmente vigente, por mais de vinte séculos, sedimentou socialmente uma visão de que o homem traria em si características como a objetividade e a racionalidade, tendo, assim, uma afinidade inata com áreas do conhecimento como a física e a matemática, por sua exatidão e "frieza”. Dada a veracidade desse argumento, inúmeras mulheres haveriam se livrado de terem sido assassinadas por seus maridos, amantes, senhores e amos, que longe de terem a referida frieza e a racionalidade que lhes seria intrínseca, impregnaram a história de sangue, em nome da honra e da vingança, sentimentos ferozes que passam longe da razão fria, capaz de conter as emoções advindas do coração.

Para além desse lamentável desvelo da dominação masculina inscrito na história da humanidade, um rápido olhar nos nomes de grandes cientistas, mulheres, reconhecidas mundialmente, por sua contribuição à ciência, basta para por em xeque argumentos que generalizam atributos como se estes estivessem inscritos nos genes. Mulheres como Marie Curie, sua filha Irene, ambas prêmio Nobel em química, em 1911 e 1935, respectivamente; Maria GoeppertMayer, prêmio de Física em 1963; Dorothy Crowfoot, em 1964; Rita Levi-Montalcini, Nobel de medicina em 1986; e tantas outras que, mesmo anonimamente, vêm fazendo cotidianamente a dita "ciência normal", projetando-se no meio acadêmico, demonstram que não há outra restrição que não a cultural para a maior afluência de mulheres ao campo da pesquisa e do conhecimento em geral.

Para analisar como o processo de geração de tecnologia está envolto em uma visão social de mundo sexista e conservadora, foi realizado um levantamento das tecnologias apresentadas pela Universidade Federal de Viçosa a produtores e produtoras rurais em um evento de abrangência nacional: a Semana do Fazendeiro, que caminha para a sua 80a edição em 2009. Esse evento foi instituído em 1929 e se consolidou a partir da criação de um Centro de Ensino e Extensão (C.E.E.), na década de 1950. Atualmente, ele mantém suas atividades anualmente para difusão de tecnologias e conhecimentos agropecuários junto aos produtore(a)s rurais. Durante esse evento, são veiculados os conhecimentos tecnológicos desenvolvidos por, praticamente, todos os Departamentos da Universidade Federal de Viçosa.

\section{MATERIAL E MÉTODOS}

Esta pesquisa de levantamento teve um caráter longitudinal, trabalhando com a coleta de dados retirados dos cursos oferecidos durante a Semana do Fazendeiro, ao longo de quatro anos, de 2004 a 2007. Correlacionou-se cada um dos cursos oferecidos na Semana do Fazendeiro com a frequência de homens e mulheres a eles. Primeiramente, foi transposta para o Excel a listagem de todos os cursos oferecidos pelos Departamentos da UFV e pela EMATER, separando os participantes por sexo. Em seguida, procedeu-se a uma condensação dos cursos, agrupando-os em 16 categorias, sendo estas: 1) tecnologias voltadas para a Bovinocultura, Suinocultura, Equinocultura, Ovinocultura; 2) tecnologias voltadas para a Agricultura; 3) tecnologias Alternativas e Meio Ambiente; 4) tecnologias voltadas para a Silvicultura; 5) tecnologias voltadas para as Aves; 6) tecnologias voltadas para o Processamento de Alimentos; 7) tecnologias voltadas para a Criação de Peixe, Minhocas, Apicultura, Escargot, Bicho da Seda, Capivara, Coelho; 8) tecnologias voltadas para as atividades não agrícolas; 9) práticas Associativas e Cooperativas; 10) Administração Rural; 11) Economia de Energia Domiciliar; 12) Máquinas Agrícolas; 13) Construções 
Rurais; 14) Água; 15) Legislação; e 16) Informática para o Meio Rural.

Realizado o agrupamento dos cursos oferecidos na Semana do Fazendeiro, entre os anos de 2004 e 2007, e formadas as 16 categorias taxonômicas, foi distribuída a frequência dos participantes dentro delas, segundo o seu sexo, como pode ser visto na tabela 1. Procedimento metodológico semelhante foi utilizado para analisar as relações de gênero nos cursos oferecidos pela EMATER. Primeiramente, foram listados os cursos oferecidos pela EMATER de 2004 a 2007 durante a realização da Semana do Fazendeiro, distribuindo a frequência dos participantes por sexo. Logo depois, procedemos à categorização dos cursos oferecidos, enquadrando-os na esfera produtiva ou reprodutiva, segundo a definição de HABERMAS (2001), anteriormente apresentada, que, apesar de ter sido problematizada neste trabalho, expressa justamente a concepção socialmente vigente, que relaciona as atividades produtivas à geração de renda e ao mercado, e as atividades reprodutivas às práticas vinculadas a família e ao ambiente doméstico, privado. Desse modo, foi enquadrada na esfera produtiva: aplicação de Medicamentos; vacinas, mutação e castração em bovinos; armazenamento de grãos na propriedade rural; avicultura como alternativa de renda e alimentação para agricultores familiares; café; conservação do solo e da água na propriedade rural; plantio direto por tração animal; produção de banana; produção de goiaba; produção de maracujá; produção de mangueira; produção de coco anão; produção de mudas de eucalipto; produção de ovinos; produção de peixes; produção de tomate; hortaliças; qualidade do leite em tanque de expansão coletiva; técnicas alternativas de produção de alimentos; produção artesanal de cachaça; e turismo rural. Na esfera reprodutiva: fabricação caseira de alimentos; formação e condução do pomar doméstico.

\section{RESULTADOS E DISCUSSÃO}

Nesta seção, são apresentados dados obtidos na pesquisa sobre as desigualdades de gênero no processo de difusão tecnológica, no campo das Ciências Agrárias, com base nos dados referentes aos cursos oferecidos durante a Semana do Fazendeiro, realizada na Universidade Federal de Viçosa. O objetivo aqui foi o de apresentar os dados que comprovariam ou refutariam a hipótese de que a prática de difusão científica no campo das ciências agrárias, embora não

Tabela 1 - Frequência de homens e mulheres nos cursos da semana do fazendeiro.

\begin{tabular}{|c|c|c|c|c|c|c|c|c|}
\hline \multirow{2}{*}{ Cursos } & \multicolumn{2}{|c|}{------2004------ } & \multicolumn{2}{|c|}{------2005------ } & \multicolumn{2}{|c|}{------2006------ } & \multicolumn{2}{|c|}{------2007----- } \\
\hline & $\mathrm{H}^{*}$ & $M^{*}$ & $\mathrm{H}$ & M & $\mathrm{H}$ & $\mathrm{M}$ & $\mathrm{H}$ & M \\
\hline Tecnologias voltadas para a agricultura & 604 & 263 & 364 & 184 & 198 & 62 & 214 & 110 \\
\hline $\begin{array}{l}\text { Tecnologias voltadas para a bovinocultura, suinocultura... } \\
\text { Tecnologias alternativas, meio ambiente }\end{array}$ & 286 & 40 & 113 & 47 & 249 & 70 & 456 & 88 \\
\hline Atividades não agrícolas & 228 & 89 & 147 & 76 & 129 & 68 & 251 & 138 \\
\hline Processamento de alimentos & 0 & 0 & 25 & 76 & 18 & 41 & 14 & 29 \\
\hline Criação de peixes, minhocas, apicultura, escargot, bicho & 189 & 209 & 76 & 94 & 43 & 99 & 31 & 40 \\
\hline $\begin{array}{l}\text { da seda, ranicultura... } \\
\text { Práticas associativas e cooperativas }\end{array}$ & 284 & 79 & 222 & 68 & 190 & 65 & 41 & 11 \\
\hline Administração da unidade produtiva & 79 & 40 & 141 & 92 & 0 & 0 & 32 & 12 \\
\hline Economia de energia domiciliar & 142 & 30 & 36 & 14 & 17 & 17 & 75 & 31 \\
\hline Máquinas agrícolas & 11 & 9 & 31 & 17 & 25 & 14 & 46 & 26 \\
\hline Construções rurais & 99 & 11 & 67 & 5 & 0 & 0 & 20 & 0 \\
\hline 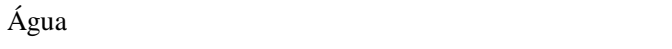 & 16 & 4 & 17 & 3 & 13 & 8 & 18 & 2 \\
\hline Legislação & 92 & 17 & 59 & 17 & 37 & 28 & 68 & 27 \\
\hline Informática para o meio rural & 65 & 20 & 23 & 7 & 90 & 43 & 0 & 0 \\
\hline Silvicultura & 0 & 0 & 23 & 7 & 21 & 10 & 0 & 0 \\
\hline Aves & 139 & 28 & 156 & 32 & 89 & 7 & 90 & 24 \\
\hline TOTAL & 35 & 12 & 96 & 49 & 76 & 32 & 59 & 21 \\
\hline & 2269 & 851 & 1596 & 788 & 1195 & 564 & 1415 & 559 \\
\hline
\end{tabular}

Fonte: Pesquisa 2008.

$\mathrm{H}^{*}$ - Homem

M*- Mulher

Ciência Rural, v.39, n.9, dez, 2009. 
exclusivamente nela, vem reproduzindo de forma acrítica hábitos culturais com viés sexista.

Um aspecto importante de ser observado nos dados apresentados na tabela 2 diz respeito ao fato de que a participação das mulheres nas atividades consideradas socialmente como produtivas é sempre muito menor que a dos homens.

Outro aspecto importante de ser destacado ao serem observados os padrões de participação de homens e mulheres nos cursos oferecidos na Semana do Fazendeiro diz respeito ao fato de que há uma relação entre as tecnologias utilizadas nas atividades produtivas e reprodutivas e os modelos de gestão da unidade produtiva familiar que consideram a mulher em uma condição hierárquica de complementaridade. Há um círculo vicioso na eleição das atividades produtivas e reprodutivas que terão prioridade dentro da unidade produtiva. Aquelas que são tipicamente masculinas são as que recebem prioridade na alocação da força de trabalho dentro da unidade produtiva, o que impõe um limite à mudança nos padrões produtivos face ao campo de possibilidades existente no mercado consumidor, tanto de alimentos, como de prestação de serviços no meio rural.

Finalizando a apreciação dos cursos oferecidos na Semana do Fazendeiro, será analisada a oferta destes por parte da EMATER, em virtude de que ela é considerada uma instituição que faz o elo entre a produção científica e a difusão tecnológica, sendo por excelência a instituição com maior potencial para influir e alterar a relação das mulheres com a tecnologia e com a dominação masculina na gestão da propriedade.

Ao destacar o viés sexista nas escolhas que os participantes fazem do curso a ser frequentado, o objetivo é mostrar que tal opção não é gratuita. Se, de um lado, ela é influenciada pelos padrões de gênero socialmente vigentes, por outro, ela é parte de um reconhecimento dos participantes quanto ao perfil sexual que se espera em cada curso. Ou seja, a própria EMATER reproduz um padrão sexista em seu habitus institucional, ao padronizar práticas de assistência apropriadas e distintas para o tratamento com homens e mulheres.
LINN (1987) argumenta que frequentemente a questão de o trabalho do homem ser definido como técnico e o da mulher como não técnico está relacionada ao fato de o trabalho não técnico ter aspectos culturais relacionados ao uso do termo "tecnologia”. Segundo a autora, o termo tecnologia tem um certo glamour, sendo interessante perceber em que contexto ele dá status. Esse aspecto implícito da tecnologia, de não ser imune aos valores sociais, é que permite perceber que a tecnologia pode ser um veículo para a diferenciação entre determinados grupos sociais. Logo, aquilo que é considerado tecnológico atribui status a um segmento em detrimento de outro. O homem é aquele que executa as tarefas consideradas como trabalho técnico, já a mulher permanece realizando atividades artesanais ou manuais.

SILIPRANDI (1999) relata essa relação de trabalho técnico e não técnico a partir dos profissionais da Emater do Rio Grande do Sul, uma vez que parte das extensionistas do sexo feminino que trabalham nas atividades intervencionistas no espaço rural riograndense enfrentam o problema de serem vistas como profissionais inferiores por parte dos agricultores e por seus colegas do sexo masculino. Isso se justificaria pelo fato de seu trabalho ser considerado menos importante por se trabalhar com a organização de grupos específicos de mulheres.

Do ponto de vista institucional, as mudanças também são percebidas como difíceis, por se considerar que introduzir as questões de gênero requer mudanças na forma de realizar os planejamentos, nos critérios de monitoramento e avaliação etc. Segundo SILIPRANDI (1999), seria necessária uma formação que permitisse elucidar as relações de poder entre homens e mulheres, a fim de realizar uma desnaturalização da divisão sexual do trabalho. Contudo, segundo a referida autora, essas mudanças de percepção dos extensionista não são capazes, por si só, de romper com uma estrutura objetivada de subordinação das mulheres rurais. Seria necessária a realização de cursos de capacitação para as questões de gênero referentes à difusão de

Tabela 2 - Categorização dos cursos oferecidos pela EMATER (Empresa de Assistência Técnica e Extensão Rural) na Semana do Fazendeiro, no período de 2004-2007, segundo os critérios de produtivo e reprodutivo.

\begin{tabular}{|c|c|c|c|c|c|c|c|c|c|c|}
\hline \multirow{2}{*}{ Cursos } & \multicolumn{2}{|c|}{2004} & \multicolumn{2}{|c|}{2006} & \multicolumn{2}{|c|}{2006} & \multicolumn{2}{|c|}{2007} & \multicolumn{2}{|c|}{ Total } \\
\hline & $\mathrm{H}$ & M & $\mathrm{H}$ & M & $\mathrm{H}$ & M & $\mathrm{H}$ & M & $\mathrm{H}$ & M \\
\hline Esfera produtiva & 370 & 76 & 374 & 154 & 178 & 102 & 211 & 83 & 1133 & 415 \\
\hline Esfera reprodutiva & 62 & 166 & 38 & 143 & 62 & 88 & 54 & 82 & 216 & 479 \\
\hline Total & 432 & 242 & 412 & 297 & 240 & 190 & 265 & 165 & 1349 & 894 \\
\hline
\end{tabular}

Fonte: Pesquisa 2008. 
tecnologia, bem como um investimento maior nas matérias publicadas pelas revistas e pelos informativos da empresa dentro desse enfoque crítico das desigualdades de gênero no âmbito do acesso ao conhecimento cinetífico-tecnológico para que essa situação pudesse ser objeto de atuação consciente dos extensionistas.

A tabela 2 permite perceber a disparidade na proporção da participação de homens e mulheres nos cursos concebidos como estando relacionados à esfera produtiva e reprodutiva. Fica claramente evidenciada a correspondência entre atividades produtivas com o público masculino e as reprodutivas com o feminino. Contudo, para além dessa tendência, pode-se observar, também, que os homens têm uma participação maior nos cursos oferecidos. Aproximadamente $60 \%$ das pessoas que participaram dos cursos oferecidos na Semana do Fazendeiro são homens. Sobressai ainda, na análise da tabela 1, o fato de não haver uma tendência de aumento da participação feminina nos cursos orientados ao longo dos anos.

\section{CONCLUSÃO}

Após análise do processo de difusão de conhecimentos científico-tecnológicos nos cursos oferecidos durante a Semana do Fazendeiro realizada pela Universidade Federal de Viçosa, observou-se que a participação feminina em cursos agrupados no tema de aplicação à tecnologia na agricultura, que exigiam conhecimentos matemáticos, conhecimentos racionais admistrativos e produtivos, foi muito menor que a masculina. Em contrapartida, nos cursos referentes ao tema de processamento de alimentos, houve uma participação majoritária das mulheres. Tal evidência de divisão sexual na frequência aos cursos corresponde exatamente ao mesmo modelo que está sedimentado na divisão do trabalho dentro das instituições de assistência técnica e extensão rural, como a EMATER. Nessas instituições, a prática intervencionista da técnica de bem-estar social nas propriedades está voltada, sobretudo, para o trabalho de administração e para os cuidados do lar, contribuindo para o papel da mulher rural como dona de casa e não como produtora, enquanto o trabalho do agrônomo ou agrônoma está voltado para a orientação tecnológica, voltado para o melhoramento da produtividade e racionalidade na gestão da propriedade, se fazendo preponderantemente junto ao homem.

Em suma, embora percebe-se que há um ambiente político favorável a uma relação de gênero mais igualitária nas políticas voltadas para o desenvolvimento rural, sobretudo, a partir da Política
Nacional de Assistência Técnica e Extensão Rural (PNATER), esta não conseguiu romper com tal assimetria nas relações de gênero, uma vez que não foi acompanhada pela capacitação de seus técnicos e técnicas em termos de perceberem os fatores culturais limitadores do acesso da mulher rural aos conhecimentos científico-tecnológicos difundidos em eventos como o da Semana do Fazendeiro.

O dado mais significativo trazido por esta pesquisa está relacionado ao fato de ter sido evidenciado o grande distanciamento das mulheres do meio rural do acesso ao conhecimento tecnológico relacionado ao seu contexto socioeconômico. Mais do que isso, não se manifesta qualquer tendência de crescimento da frequência destas a eventos de acesso ao conhecimento técnico que lhes capacite e lhes dê legitimidade para compartilhar as diretrizes de gestão na unidade produtiva. Já os homens reforçam sua assimetria de poder de mando e decisão na propriedade ao se atualizarem e capacitarem tecnologicamente.

Nem mesmo se forem consideradas as atividades relativas ao processamento de alimentos, as quais têm uma maior interface com as atividades consideradas reprodutivas e, por isto, próprias às mulheres, a participação feminina chega a ser tendencialmente consistente. Ou seja, a baixa participação feminina é nos cursos não é nem pelo fato de grande parte deles estar voltado para a esfera concebida como "produtiva” e, portanto, serem vistos como destinados ao homem, mas, antes, a frequência das mulheres não é constante e nem crescente nos cursos voltados para a esfera dita reprodutiva, porque simplesmente conhecimento e qualificação não são concebidos socialmente como sendo para ela.

Culturalmente o conhecimento tecnológico, qualificador da posição profissional de produtora rural, não está construído, visto que a mulher rural é vista como aquela que ajuda, ela é a dona de casa, mas não uma produtora rural. Daí que a busca por se qualificar dentro da sua profissão não está interiorizada nela mesma, nem construída socialmente, como uma expectativa a ser realizada. O conhecimento tecnológico não se destina à mulher rural porque ela é alguém que não pertence à esfera pública, da economia, da profissão, da política, do associativismo.

Assim, sem contar potencialmente com a qualificação produtiva de cerca da metade de sua população, o meio rural brasileiro amarga índices muito baixos de produtividade, uma qualidade de vida deplorável e uma falta de perspectiva de mudança de lugar na hierarquia social e familiar, que em tudo estimula a saída das moças do meio rural, deixando o meio rural cada vez mais com uma cara masculina. 


\section{REFERÊNCIAS}

BENERIA, L. La mujer y el genero en la economía. In: VILLOTA, P. Economia y gênero. Barcelona: Içaria, 2006. p.23-75.

BUTLER, J. Problemas de gênero. Feminismo e subversão da identidade. Rio de Janeiro: Civilização Brasileira, 2003. 236p.

FRASER, N. “O que é crítico na teoria crítica? O argumento de Habermas e o gênero". In: FRASER, N. et al. (Orgs.). Feminismo como crítica da modernidade. Rio de Janeiro: Rosa dos Tempos, 1987. p.38-65.

HABERMAS, J. Técnica e ciência como ideologia. Lisboa (Portugal): Edições 70, 2001. 147p.

HARAWAY, D. Saberes localizados: a questão da ciência para o feminismo e o privilégio da perspectiva parcial. Cadernos Pagu, Campinas, n. 5, p.7-42, 1995. Disponível em: <http:// www.pagu.unicamp.br/files/cadpagu/Cad05/pagu05.02.pdf $>$. Acessado em: 12 ago. 2009.

HARAWAY, D. et al. Antropologia do ciborgue. Belo Horizonte: Autêntica, 2000. 142p.
HARAWAY, D. "Gênero para um dicionário marxista: a política sexual de uma palavra”. Cadernos Pagu, Campinas, n.22, 2004, p.201246. Disponível em: <http://www.scielo.br/scielo.php?pid=S0104$83332004000100009 \&$ script $=$ sci_abstract\&tlng=pt $>$. Acessado em: 12 ago. 2009. doi: 10.1590/S0104-83332004000100009.

HARDING, S. Whose science? Whose knowledge? Itaka (NY): Cornell University, 1991. 338p.

LATOUR, B; WOOLGAR, S. A vida em laboratório: a produção de fatos científicos. Rio de Janeiro: Relume Dumará, 1997. 310p.

LAURETIS, T. A tecnologia do gênero. In: HOLLANDA, B.H. Tendências e impasses: o feminismo como crítica da cultura. Rio de Janeiro: Rocco, 1994. p.13-44.

NICHOLSON, L. Interpretando o gênero. Revista Estudos Feministas, Florianópolis, v.8, n.2, p.9-41, 2000.

RUBIN, G. Reflexionando el sexo: notas para uma teoria radical de la sociedad. In: SCHIENBINGER, L. O feminismo mudou a ciência? Bauru, SP: EDUSC, 2001. 384p. (Coleção Mulher). 